International Journal of Literature Studies (IJLS)

ISSN: $2754-2610$

DOI: $10.32996 /$ ijts

Journal Homepage: www.al-kindipublisher.com/index.php/ijlss

\title{
Geo-environmental Factors in Three Persian Folk Stories: A Preliminary Study
}

\author{
Fatemeh Shafiei ${ }^{1} \square$ and Habibollah Ghassemzadeh ${ }^{2}$ \\ ${ }^{1}$ Ph.D. Cognitive linguistics, Institute for Cognitive Sciences Studies, Tehran, Iran. \\ ${ }^{2}$ Professor, Ph.D. Developmental/ Clinical Psychology, Department of Psychiatry. Tehran University of Medical Sciences, Iran
}

$\square$ Corresponding Author: Fatemeh Shafiei, E-mail: s.shafiee@alumni.ut.ac.ir

\section{ARTICLE INFORMATION}

Received: 21 October 2021

Accepted: 12 November 2021

Published: 28 November 2021

DOI: $10.32996 /$ ijts.2021.1.1.10

\section{KEYWORDS}

Mental Spaces, Cognitive

Narratology, Storytelling,

Conceptual Blending

\section{ABSTRACT}

Stories mirror the essential function of human cognitive activity. In the present preliminary study, we hypothesized that the mental spaces that make up the stories can be influenced by the environmental conditions of their creators. For this purpose, three stories from three different climatic zones in Iran were selected and a content analysis method was used to analyze their components. Results showed significant differences between the mental spaces of different geographic regions in these three stories. This finding could be considered as a step taken to show the extent to which an individual's cognition and cognitive processing in general and the creation of meaning in particular, is an extension and representation of embodied experience. We have discussed the subject in the framework of narrative analysis as well as cognitive semantics.

\section{Introduction}

\subsection{Theoretical background}

The narrative has been defined as "the representation of a story (an event or series of events) (Abbott, 2008:13). As the word representation suggests, the narrative is a cognitive process that can be studied in the different cognitive sciences. Cognitive linguistics as one of these sciences is based on the premise that language is not only the product of specific, predetermined structures in the brain but also the result of general (shared) cognitive systems that humans can conceptualize for all aspects of reality. This hypothesis has been extensively discussed and formulated by Turner $(2006,1996,1991)$ and Fauconnier and Turner (2002) in a way that makes it possible to examine the relationship between literature and everyday language as well as specific linguistic phenomena such as literary language. One of the main manifestations of literary language is materialized and expressed in the form of stories. As a matter of fact, we conceptualize our experiences and understanding in a frame that stories are the most known forms of that frame. Stories are formed according to thought processes which are mainly organized in language structure and therefore, they could be recognized as the proper subject of cognitive science. As Hogan explains in his book Cognitive Sciences, Literature, and The Arts, if cognitive science fails to put literature, poetry, and art - which are pivotal to human thought, culture, and practice - in the center of attention, "it will be left on the dust heap of history" (Ghassemzadeh, 2015, Hogan, 2003: 3). Accordingly, cognitive linguistics, one of the disciplines or areas of study of cognitive science, has focused on the close relationships between experience, language, and cognition, and has provided a suitable context for literary analysis from the standpoint of a cognitive approach. In this regard, Mark Turner emphasized language as a cultural and mental activity that represents itself in literature (Turner, 1991: 24). Gibbs, on the other hand, believes that narratives play an essential role in revealing the general (shared) mental processes that lie beyond any narrative production (Gibbs, 1994). Consequently, most narratives are shaped and displayed in the form of stories.

In fact, stories mirror the essential function of human cognitive activity that is inseparable from culture. One of these cognitive functions, called conceptual blending, makes it possible to deepen the textual analysis of narratives. In this theory, the text is not considered the final product, but rather a process that is determined by specific cognitive elements and the integration of different mental spaces (Barekat, \& Rowshana, \& Mohamadebrahimi, \& Ardebili, 2012). What is regarded in conceptual blending theory

Copyright: (C) 2021 the Author(s). This article is an open access article distributed under the terms and conditions of the Creative Commons Attribution (CC-BY) 4.0 license (https://creativecommons.org/licenses/by/4.0/). Published by Al-Kindi Centre for Research and Development, London, United Kingdom. 
comes from the proposed mental spaces. Then, it is of crucial importance to study and analyze the way these spaces are formed in the conceptual blending theory and, in turn, to study stories and narratives from a cognitive perspective.

\subsection{Narrative and Cognitive Semantics}

According to Claude Levi-Strauss (1974), the narration is one of the earliest and most powerful artefacts of human cognition. Jerome Bruner (1986) also considers narration as one of the two separated cognitive modes of knowing the world, a paradigmatic and a narrative, and argues that narrative enables one to construct social realities.

In his book Literary Mind, Mark Turner also argues that narration provides a cognitive and communicative environment in which one can make dynamic and point-by-point comparisons between seemingly different events and situations. Accordingly, cognitive narratology can be defined as the study of aspects pertinent to the mind in storytelling. The cognitive narrative encompasses a broad and extensive definition, while its ultimate goal, and actually the purpose of all aspects of narrative analysis from a cognitive perspective, is to understand what processes the story world constitutes and what cognitive elements comprise it. One of the elements that have a fundamental role in shaping the world of the story is the conceptual blending and how mental spaces are created next to each other. The blending theory proposes a model of four or more spaces as opposed to two domains which act as a prototypical example in the conceptual metaphor theory (Kövecses, 2010). In the blending theory, there is no claim of unidirectionality of projection. And most importantly, in the blending theory, the main focus is on novel conceptualization or an "emergent meaning", whereas conceptual metaphor theory focuses on entrenched conceptualization (Fauconnier \& Turner, 2002). In fact, conceptual blending occurs from the moment of production and understanding language and is a fundamental process in the simplest form of thought and reasoning to the most sophisticated level of literary creation and is unconsciously represented in all aspects of human life. One of these aspects is the story, of course. It seems that when analyzing stories from a cognitive point of view, one can trace the cultural and geo-climatic components that influence the formation of stories and are reflected in their environment by studying the mental spaces involved in conceptual blending. It can also help to show whether peripheral realities such as geo-climatic and cultural factors influenced the minds of the story-makers and whether the mental spaces that constituted the stories could reflect those factors. By geo-climatic factors, we mean changes in the earth's climate system which result in new weather patterns that remain in place for an extended period of time. This length of time can be as short as a few decades to as long as millions of years. Before contemplating and answering the mentioned question, it is better to first provide a definition of mental space in Fauconnier's theory and present a more accurate picture of it.

\subsection{Mental Spaces}

In cognitive semantics, the meaning is treated as the constructive outcome of structures and sentences along with words. In this view, sentences construct temporary conceptual domains that emerge in discourse. The meaning of these structures and sentences occupies what Fauconnier calls a 'space', which is interconnected with other spaces through 'vital relations'. According to this view, meaning comprehension is not limited to understanding the meaning of the sentence, and not all the meaning of the sentence is limited to knowing the meanings of the words. What is important is constructing the meaning through the entire sentence which is referred to as conceptualization. The theory of mental space as was put forward by Fauconnier $(1994,1997)$ that the meaning of sentences cannot be examined separately from the context and the words. In other words, semantics cannot be separated from pragmatics, that is, the contextual meaning. In the classic literalist view, the meaning of each sentence is determined by its truth and falsehood in relation to the outside world, while in the cognitive perspective, the realities of the outside world represented themselves in language as an embodied experience (Evans \& Green, 2006).

Mental spaces are interconnected when thinking and discourse are revealed through different mappings, especially in the form of identity and deductive mappings. In addition, it is assumed that the mental spaces at the neuronal level are a set of activated neuronal communities. When the elements and connections of mental space are organized as a package that we already know, then we say the mental space is organized and this created organization is called a semantic framework or format (Fauconnier, 1994).

Mental spaces are created from many sources. One of the sources is the conceptual areas we have fairly learned, such as eating and drinking, buying and selling, social dialogue in public spaces, and the like. A single mental space can consist of many separate conceptual domains. Another source of mental space is the experience of the moment or the experience of the current moment. And finally, the third source involved in the formation of mental spaces comes from the things people talk to us about (Keshavarz \& Ghassemzadeh, 2008). To better understand these three sources, consider the following example: "Sarah shops at a pastry shop". The conceptual domain of "shopping" is involved in forming the mental space of this sentence. In addition, if you see Sarah at the moment shopping for a pastry shop, the "Sarah in the pastry shop" mentality is created in your mind. And finally, if someone tells you that Sarah has gone to the pastry shop, the mental space associated with that sentence will actually come to your mind. 


\section{Method}

In this study, we have used a version of the content analysis method. Content analysis is a research method used to identify patterns in recorded communication. To conduct content analysis, one systematically collects data from a set of texts, which can be written, oral, or visual. Content analysis can be both quantitative (focused on counting and measuring) and qualitative (focused on interpreting and understanding). In both types, you categorize or "code" words, themes, and concepts within the texts and then analyze the results. In other words, content analysis is the study of documents and communication artifacts, which might be texts of various formats, pictures, audio, or video. Social scientists use content analysis to examine patterns in communication in a replicable and systematic manner (Bryman \& Bell, 2011). For example, the method used in the article The Wise Man and Collective Memory in Sa'di's Rose Garden: A Cognitive-Narrative Analysis (Ghassemzadeh, 2009) is based on the content analysis method. In this study, the researcher has selected a story from Sa'di's Gulistan and analyzed it in five levels of processing from a cognitivenarrative perspective based on a content analysis method.

In the present study, after the selection of the stories, the content analysis method was used. For example, in story number 1 , the general picture of the story was first extracted and then the main elements of the story were identified. Then, how the author deals with the concept, here Deev, and how to use the main elements of the story, in connection with this concept was examined and analyzed.

\subsection{Investigating the Mental Spaces in Three Selected Stories}

After a brief discussion of the cognitive narrative and mental spaces, it would be interesting to consider the relation of narration to the peculiarities of the real environment as happen in the geo-climate conditions. Our specific hypothesis is that the mental spaces that make up the stories can be influenced by the environmental and cultural conditions of their creators. For this purpose, three stories from three different climatic zones in Iran were selected.

\subsection{The procedure for selecting stories}

Two conditions were considered for selecting the stories: First, it was necessary for the narrators of these stories to be ordinary, local, and indigenous people of each region. Second, all three stories had to have at least one common concept in order to better explore the existence or absence of differences and similarities in how the story spaces were created. Ensuring both criteria were met made the task highly difficult and time-consuming. But eventually, we succeeded.

After much effort, the stories were selected: two stories from a multi-volume book series called Iranian Myths (2011), compiled by Zahra Mohajeri, and another from Gilan's Myths (2012), compiled and edited by Hadi Gholamdoust. The stories collected in these series, according to their authors, are all folklore and narrated in the language of ordinary people. The common sense in these three stories is the concept of "demon" (Deev). Although it is mentioned as the "giant" in one of the stories, it is meant to refer to the concept of "demon". Deev is a familiar, but the conceptually vague and ambiguous word that has formed part of people's beliefs at different periods of time. The word has been prominently used in popular literature and talked about in various ways. Although it has a long history in the mythological literature, the concept of Deev has been extensively mentioned in major classic works such as the Shahnameh (By Firdowsy, The Epic of Kings) as well as in contemporary literature. Sometimes they are portrayed with strange faces and enormous bodies, portrayed as having a wicked and transgressive nature, and other times (not very frequently), extraordinary actions and kind images have been attributed to them.

\subsection{Human mind and the concept of Deev in literature}

The primitive, simplistic mind of the early human attributed all things to unknown factors or phenomena. These factors and phenomena were considered supernatural forces making humans subordinate and powerless. As these supernatural sources could not be sacred Gods, they were referred to as anti-Gods and demons. For example, in the mind of early humans, earthquakes, hurricanes, droughts, severe winter cold, barren fields, salty lakes, bare mountains, and any other natural disaster belonged to the demons (Mole, 1998: 58). In the theory of Julian Jaynes (2000), a human who lived in the Neolithic Age and had a language system, from about ten thousand years BC to a millennium BC, had a bicameral mind. Jaynes believes that the population of human flocks grew and language became an effective means of communication between humans living in large numbers in a single social unit. But gradually a transition happens from living in social units consisting of a limited number of people (herds or families or tribes, and settlers or tenants) to more dispersed social units, such as the villages of a region or cities of several thousand people happened. At this time, those human societies that were capable of having a bicameral mind and could hear the voices and commands of the gGods defeated the other humans who lacked this feature and pulled them out of the race, and in fact, these types of humans won in the race by natural selection because they had undeniable advantages over non-bicameral-minded humans. Julian Jaynes says that bicameral-minded people lacked consciousness and had nothing called "me" or "self". He says that about $1500 \mathrm{BC}$, with the eruption and activity of the volcano Terra in northern Crete, the Mediterranean climate changed and mass migration led to the destabilization and collapse of many civilizations and empires. And the bicameral-minded man could not adapt himself to new conditions. So, the bicameral mind collapsed and a cultural phenomenon called consciousness, of course, in its early stages was formed. Consciousness as a new cultural phenomenon was able to create a new type of human being 
(culturally) able to think more flexibly and to mislead and deceive his audience if necessary (Jaynes, 2000). But a bicameral-minded man was lacking such an ability to deceive, lie, and betray. Many civilizations and governments and even empires collapsed as volcanoes activated and mass migrations from one region to another led to clashes and wars between immigrants and natives. Now the conditions had changed so much that the Gods who were the product of the human dual mind and who had the right hemisphere of the human mind as the place of their oral commandments could not adapt themselves to the new conditions. "The invention of writing was a factor that contributed to the collapse of the mind, along with geographical and environmental factors, migrations, volcanoes, wars, and the collapse of empires and civilizations," says Julian Jaynes. The invention of writing helped to develop consciousness and created conditions in which (in his view) the voices of the Gods were silenced and prevented from speaking to humans.

About the primitive mind of the early human Claude Levi-Strauss (1966) believes that the creature that we know so-called human beings, at any time in history, always has his mind and subjectivity in this world derived from a "manner." That is, this creature always understands himself, the world, and his problems by means of the manner in which he exists. In Levi-Strauss's explanation, we find that the mental state of the primitive man was probably based on sensory perceptions, presumably because of his primitive living conditions. That is to say, given the dialectical relationship he/she has with his/her social environment, it is now inevitably understood by the sensory perception of the environment that he/she has come into being, and today, this manner is becoming more subjective day by day because of changing social environment's structures. For example, it could be argued that if in the wilderness (just as a life history term) wild man was subject to the law of the forest, thousands of years later, with the advent of urban societies, legal rules would be replaced for forest laws.

Thus, as we can see, it is clear from Levi Strauss's statement that this manner of life and culture belongs to what constitutes mental quality. In other words, whether the mind can use the communication of the new world or have a very high emotional connection to the plants, animals or the environment depends directly on the material and cultural conditions of his way of life. The human brain is the same everywhere and the limitations of the functioning of the mind are the same. But this mind is not always faced with similar problems. These issues take a variety of forms due to factors such as geographic environment, climate, the status of civilization at a given time, the ancient and contemporary history of that community, as well as about individual members of society, their moods, personal history, and individual circumstances in groups and so on. The machine is similar everywhere, but the input and output are changing (Levi Strauss, 1966: 88). Before Levi Strauss, Lucian Levy-Bruhl (1922), had accepted a similar position claiming that it is the function of thought that changes in the course of history, not the unit of thought as some of the associationists (such as Rivers) would accept it.

\subsection{The linguistic aspects of the word Deev}

Linguistically, Deev is a word that is derived from the Greek word Diabolos/Damion, which means a very malevolent spirit, evil spirit, contender, or enemy. Deev as an ancient word stands for God to Hindu Aryans. In the Hindu Sanskrit language, Daevah or Deva means light and God and retains its sanctity to the day. The derivations of the word Deev among the Aryan tribes also contain the meaning of God; it is Daeva in Avestan Persia, Dev in Pahlavi, and becomes Deev in Dari Persian. After going through the Zoroastrianism reforms, it takes on a negative meaning and refers to the forces of evil (Afifi, 1995; Mole, 1998). Indeed, in ancient Iran, the demons were a group of Aryan lords, but after the separation of the Iranians from the Hindus and the advent of Zarathushtra, they were regarded as ashtrays and demons.

Amid Dictionary (under the word Deev) defines Deev as a fantastical and legendary creature whose body resembles a human but very vigorous, ugly, enormous, and with a horn and tail. Some of the features attributed to Deev in this dictionary include being malevolent, ruthless, foolish, insane, dark-skinned, bald-headed, stubborn, and at the same time, fearless and valiant. Moin Encyclopedic Dictionary also regards Deev as an imagined creature who is portrayed as tall, stout, obnoxious, and terrifying, with two horns on his head and a tail. In this dictionary, the attributes or names of the devil, and traits like evil, wild and desolate, seductive, malicious, ignorant, and such are all attributed to Deev. It also considers Deev a daring, courageous, strong, bold, old, and valiant creature. We see in Dehkhoda Dictionary the words devil, evil, and Satan as synonyms for the word Deev. Dehkhoda explains that "in Zooroastrian religion, any untrue God or malevolence that in fact was a manifestation of sin and evil was regarded as Deev" adding that "Persians called every rebellious and disobedient being, whether of man, jinn, or of animals, a Deev and those who did good, would be called angels". Based on what has been said, and given the definition of the word Deev in the three mentioned dictionaries, it can be said that Deev has two faces in the beliefs of our predecessors and is considered a mixture of benevolence and evil, or good and bad-a bad feature being dominant, of course.

The concept of Deev can also be viewed from the perspective of mythology. From the point of view of Mehrdad Bahaar, a famous Iranian historian and mythologist (1998), myth is a set of interactions between the socio-human and natural factors that pass through the psyche of the human being, adapting to his various psycho-social needs and appearing by his proper rituals, and its purpose is to create a compromise between man and his psychological complexity with nature around him (Bahaar, 1998: 411). Bahaar (1998) believed that myths and human beings of nations are in constant change. As the old social relations can change, 
the superstructures of those old social relations also change and fill in new things. Therefore, the departure of the Firdowsi's Shahnameh's or Shakespeare's writings from the contemporary lives of the Iranian and British peoples is natural and inevitable and should not be regretted. In his view, what is important is that the human mental world is not left empty for any period, and if it leaves the mythological heroes of the past behind, it will replace the new heroes, who in practice are the same as they used to be. In fact, today, instead of Siavash's (an important character in Shahnameh) story being general, the lives of the other heroes concerned with the underpinnings and superstructures of this time are raised (p. 362). Because the objective conditions of society and the environment around us have changed so much in our time that our modern-day hero can no longer live like Siavash, but can have Siavash's spiritual qualities (Bahaar, 1998: 364).

\subsection{Analyzing the mental spaces of the selected stories}

Now, we turn to the stories that revolve around the concept of Deev. Selected stories in this study are; Chaker Charcham (Four Eyed Servant) from Jask Port in Hormozgan Province near the Persian Gulf and Oman Sea, south part of Iran, The Giant and Hassan from Gilan Province in the north of Iran, and the story of Black Deev and the Brave Boy from Sabzevar in Razavi Khorasan, eastern province of Iran.

In the Gulf region, the stories seem to have a deep connection to water. The myths from the Persian Gulf are often joined at one axis, and that is dependence on water, whether it is the water of the blue sea on which the coast inhabitants rely for a living, or it is the rain that quenches the thirst of people by the sea. On the other hand, there is a sea in the northern region of Iran, and besides, there are also forests, farmlands, and paddy fields due to the specific climatic conditions, and this is probably the main strength of the people. Meanwhile, Khorasan Province has neither the gulf nor the sea, nor the forest or paddy fields. The people of this land mostly earn a living through jobs such as cashmere knitting, wheat harvests, livestock, and the likes.

Given the aforementioned bio-cultural background, we now turn to three stories from these three regions and examine the materialization and/or actualization of the concept of Deev in each story.

\subsubsection{The First Scene: Blue Coast of Persian Gulf, Hormozgan, Jask Port: Chaker Charcham (Four Eyed Servant)}

The story is told by the 40-year-old Ms. Alieh Sepehrian from Jask Port. It is about a man and his wife who have four sons but they wish to have a daughter. Things happen during the story as they hope to get their wish until the story reaches the point where one of their sons, Charcham, has to fight the Deev:

"...Chaker Charcham made his way west and went up and down until he reached a village. In that village, all the trees had dried up and all the animals and humans were thirsty. He saw a girl and asked, "what has happened to you?" The girl said "Do you see the other side of the village? A gigantic demon (Deev) is blocking the source of our water, not allowing water to come over to this side." Chaker Charcham said "I will take care of this gigantic Deev," (Iranian Myths, Sixth Edition, page 83).

In this story, the "demon" quality of the Deev - its malice - is depicted as "closing the water gateway on the villagers". On the other hand, in the continuation of the story, when Chaker Charcham wins the fight against the Deev, he does not kill him. In return, the Deev promises to help him and the villagers. This might be attributed to the reproductive quality of water, which has proven itself in destroying the devil in the Deev. In this story, unlike most other folklore, the demon is not destroyed and, quite the opposite transforms into a good and helpful being.

\subsubsection{The Second Scene: North of Iran, Gilan: The Tale of the Giant and Hassan}

The narrator of this story is unclear, but its collector, Hadi Gholamdoust, acknowledged that the legends from Gilan (a province in the north of Iran, near the Caspian Sea) have been a product of more than three decades of living between the people of Gilan inside and outside of cities, and have been quoted by the local and indigenous people. In the Tale of the Giant and Hassan, the main subject of the story is harvesting paddles and how to carry them home:

"...Once upon a time, there was a boy named Hassan who gathered paddles he harvested in the paddy field and arranged to return home the next day... "(The Myths of Gilan, page 91).

The story continues until we see Hassan come across a giant (Deev) on his way back home in the middle of the road. The Deev asks Hassan to wrestle with him, or he would be killed otherwise. Hassan grapples with him and triumphs over the giant. Hassan uses a bag of flour and nails in this battle.

The interesting point about the materialization of this story is that it uses wrestling, one of Gilan's local championship sports. This cultural component is actually used to defeat the Deev. In addition, in the Tale of the Giant and Hassan, the giant is found in the middle of the forest and the paddy field, which specifically points to another aspect of environmental influence (the forest) for the formation of mental space. 


\subsubsection{The Third Scene: Khorasan, Sabzevar, eastern province of Iran: The Black Deev and Brave Boy}

The narrator of this story is Ms. Rahimeh Rahmati, seventy-five years old from Sabzevar. In the story of the Black Deev and the Brave Boy, there is neither water nor a sea, not a forest or a paddy. The general atmosphere of the story is depicted with the dark sky and black smoke and black clouds. Wherever there is talk of a demon, there is also black smoke.

The story revolved around two siblings who have lost their parents and are living together. One of the days when the sister leaves home for a bath, she does not return back home. The worried brother asks about his sister from the public bath owner. The owner says:

"... I saw a girl and when she came out of the bathroom, a dark cloud appeared in the middle of the sky. The girl looked up at the sky and followed the black cloud..." (Iranian Myths, Second Volume, page 107).

Over the course of the story, the boy arrives at an unfamiliar place after some searching.

"...after a few days of walking, he saw from a distance a lot of smoke going up from behind a mountain... When he looked inside the cottage, he saw a black Deev lying on a bed while his sister was blowing him... "(Iranian Myths, Second Volume, page 108).

The story continues, and the boy contemplates finding a way to destroy the Deev to save his sister. Eventually, he finds the Deev's life crystal, and by breaking it, the Deev is destroyed:

"...the Black Deev shrieked and turned into smoke and went up into the air..." (Iranian Myths, Second Volume, page 109).

In this story, Deev is portrayed using the mental space of black smoke and black clouds, and the path the boy takes to rescue his sister constitutes mountains and a desert.

\section{Discussion}

We can summarize the conclusion as follows: 1) the scenes present the most salient and conventional aspects of life in different parts of Iran as they occur in ordinary situations and occasions; 2) explorations and struggle happen whenever something goes awry or something bad happens; 3) Deev has been introduced in Iranian culture as a devil, strong and cruel creature and the main character of the story needs to think and find a way to get rid of that bad being. In the first scene, however, its nature changes to a good being, which requires some explanations.

The schematic presentation of events in the 3 scenes has been shown in Figures 1,2 and 3 .

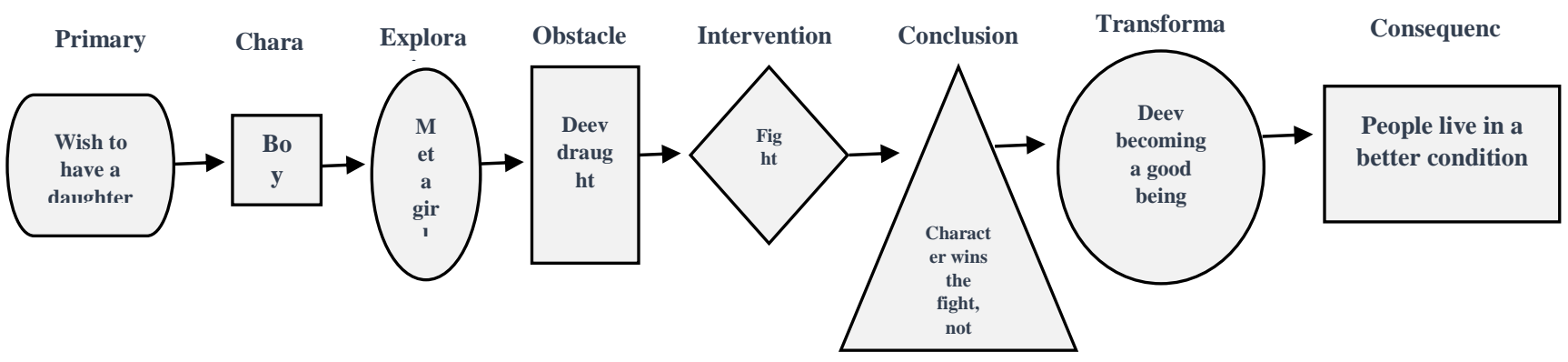

Figure 1. The schematic presentation of events in the story 1

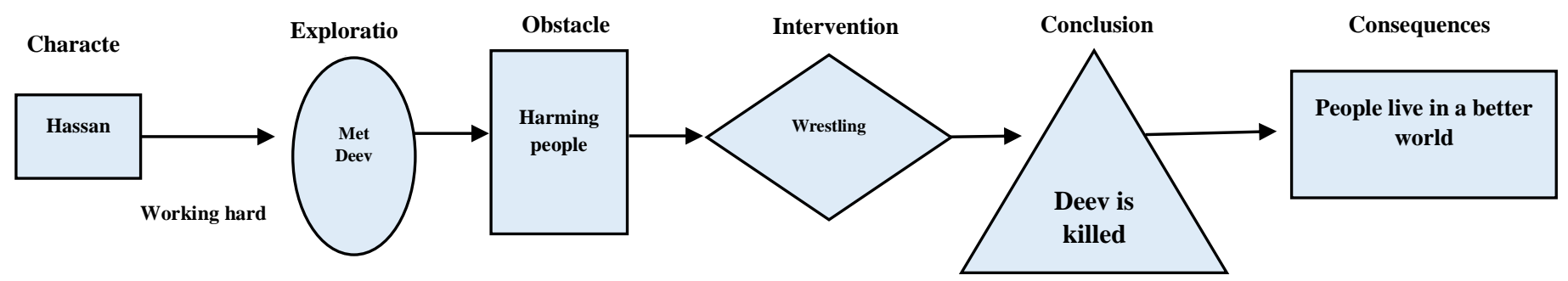

Figure 4. The schematic presentation of events in story 2 

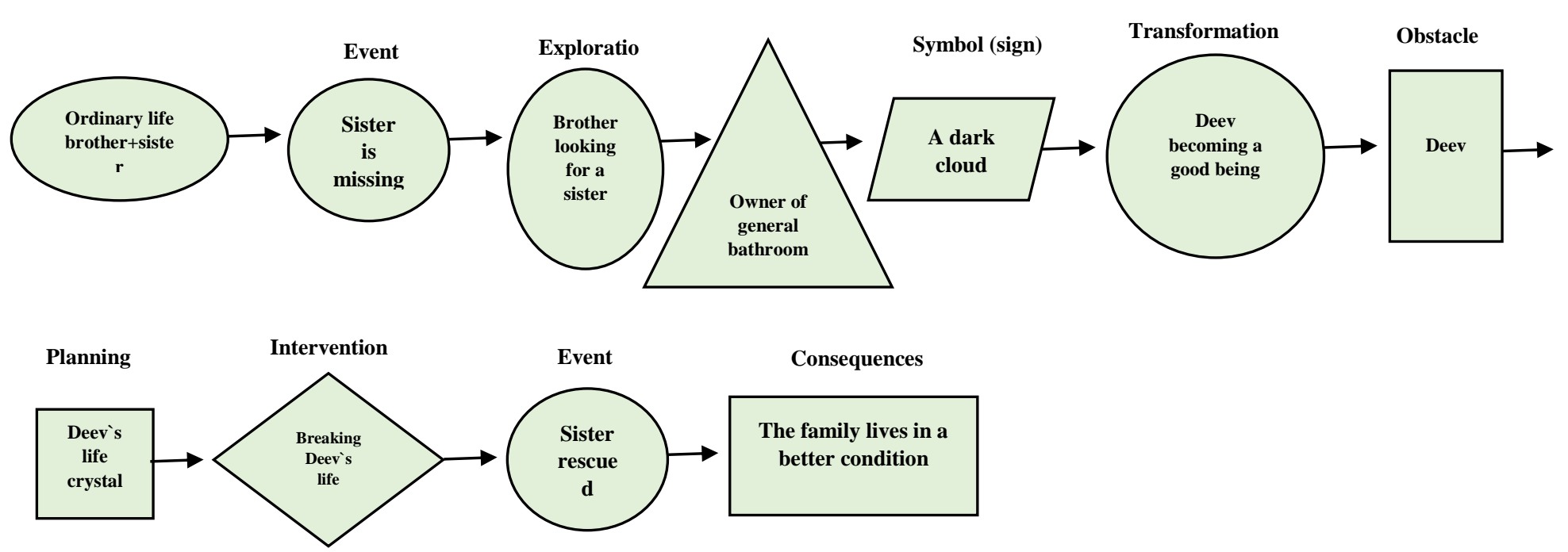

Figure 5. The schematic presentation of events in story 3

In all three stories, the influence of geo-climatic and, to some extent, cultural factors are evident. We have seen how different the concept of imagination of a certain word, here Deev, is in the three different areas, and to what extent the difference depends on the features surrounding them. In addition to the differences seen in the depiction of Deev in the stories, there are other subtle points to be found throughout the folklores. For example, in the first story, Chaker Charchem chooses dates and water for his dietary strength, while in the third story; his strength comes from bread and water. This difference in the type of food certainly refers to both the geo-climatic factors that made the food available to each of these regions and can also have roots in the peoples' nutritional habits from each land.

Furthermore, the environmental impact of the natural surroundings is evident even in the titles of many legends. For example, in the myths of Gilan, north of Iran, the words rice which is the main food of the people of that land, a cluster of rice, paddles, paddy, and similar words are used extensively, while in the southern and near-Persian Gulf tales, more often than not, keywords include dates, palms, etc. In places like Khorasan, the eastern province of Iran, the words often used in the titles of stories are related to the occupation of the person, such as thorn-picker, cobbler, etc., and titles include words such as rice, paddy, and fish are rarely seen.

Although significant differences between the mental spaces of different geographic regions can be seen in these three stories, they are not solely influenced by environmental and cultural factors, and in many cases, the author's own personal life and internal experiences are also a source of influence for the stories.

\section{Recommendations and Conclusion}

The last point that could be considered in the present study may come across as simple at first glance is the problem of creating meaning and conceptualization based on experience, as has been formulated in different contemporary perspectives. The pioneers of theories based on human cognition and cognitive linguistics consistently believe that the foundation of linguistic studies must be meaning-based and that consideration of meaning must take into account human cognitive abilities and embodied experience. But on the other side of this continuum, there are linguists who take a dim view of meaning in their linguistic theories and do not care about experience or embodiment of meaning. Thus, studies and investigations such as the one that is explained in this paper could be considered as a step taken to show the extent to which a person's cognition and cognitive processing in general and the creation of meaning in particular, is a continuation and representation of embodied experience.

Funding: This research received no external funding.

Conflicts of Interest: The authors declare no conflict of interest.

\section{ORCID}

Fatemeh Shafiei: https://orcid.org/0000-0003-4730-125X

Habibollah Ghassemzadeh: https://orcid.org/0000-0003-4180-1093 


\section{References}

[1] Abbott, H.P. (2008). The Cambridge introduction to narrative. Cambridge: Cambridge University Press.

[2] Afifi, R. (1995). Persian mythology and culture in Pahlavi writings. Tehran: Toos.

[3] Amid, H. (2011). Amid Dictionary. (Vol. 1, Below the word "Deev"). Tehran: Amirkabir.

[4] Bahaar, M. (1998). From Myth to History. Tehran: Cheshmeh.

[5] Barekat, B., \& Rowshana, B., \& Mohamadebrahimi, Z., \& Ardebili, L. (2012). Cognitive Narratology: Applying the conceptual blending theory to Persian folk tales. Adab Pazhuhi, 6(21), 9-31. https://www.sid.ir/en/journal/ViewPaper.aspx?id=503446

[6] Bruner, J. (1986). Actual Minds, Possible Worlds. Harvard University Press.

[7] Bryman, A., \& Bell, E. (2011). Business research methods. Cambridge: Oxford University Press.

[8] Dehkhoda, A. (1998). Dehkhoda Dictionary. (Vol. 8, Below the word "Deev"). Tehran: Tehran University Press.

[9] Evans, V. \& Green, M. (2006). Cognitive Linguistics: An Introduction. Edinburg: Edinburg University Press.

[10] Fauconnier, G. (1994). Mental Spaces: Aspects of Meaning Construction in Natural Language. Cambridge: Cambridge University Press.

[11] Fauconnier, G. (1997). Mappings in Thought and Language. Cambridge: Cambridge University Press.

[12] Fauconnier, G. \& Turner, M. (2002). The Way We Think; Conceptual Blending and the Mind's Hidden Complexities. New York: Basic Books.

[13] Ghassemzadeh, H. (2009). The Wise Man and Collective Memory in Sa'di's Rose Garden: A Cognitive-Narrative Analysis. International Journal of Humanistic Ideology, 2, No 1, 135-165.

[14] Ghassemzadeh, H. (2015). From Mandelstam`s Hall of Shadows to Hafiz's On The Marge of the Passing Stream. Brain, Cognition, and Behaviour: A Collection of Seminar Papers, Book 2, 85-122.

[15] Gholamdoost, H. (2012). Guilan myths. Tehran: Neagah.

[16] Gibbs, R. W. (1994). The Poetics of Mind. Cambridge: Cambridge University Press.

[17] Hogan, P. C. (2003). Cognitive Science, Literature, and the Arts. London: Routledge.

[18] Jaynes, J. (2000). The Origin of Consciousness in The Breakdown of The Bicameral Mind. Boston: Mariner Books.

[19] Keshavarz, F., \& Ghassemzadeh, H. (2008). Life as a stream and the psychology of "moment" in Hafiz verse: Application of the blending theory. Journal of Pragmatics,40, 1781-1798. https://doi.org/10.1016/j.pragma.2007.11.011

[20] Kövecses, Z. (2010). Metaphor: A practical introduction. Second edition. New York: Oxford University Press.

[21] Levi-Bruhl, L. (1922). Mentalité primitive. Paris: Alcan.

[22] Levi-Strauss, C. (1966). The Savage Mind (The Nature of Human Society Series). Chicago: The University Of Chicago Press.

[23] Levi-Strauss, C. (1974). Structural Anthropology (Revised ed.). New York: Basic Books.

[24] Mohajeri, Z. (2011). Iranian myths. Mashhad: Behnashar.

[25] Moin, M. (2009). Moin Encyclopaedic Dictionary. Below is the word "Deev". Tehran: Amirkabir.

[26] Mole, M. (1998). Ancient Persia (J Amoozegar, Trans.). Tehran: Toos.

[27] Turner, M. (1991). Reading Minds: The Study of English in the Age of Cognitive Science. Princeton: Princeton University Press.

[28] Turner, M. (1996). The Literary Mind. Oxford: Oxford University Press.

[29] Turner, M. (2006). The Artful Mind: Cognitive Science and the Riddle of Human Creativity. New York: Oxford University Press. 